\title{
Comparison of the effects of anaerobic and micro- aerophilic incubation on resistance of Helicobacter pylori to metronidazole
}

\author{
Y. M. ABDI, K. A. YOUNG*, D. S. RAMPTON†, J. M. HARDIE*, R. A. FELDMAN $\ddagger$ and \\ N. BANATVALA $\ddagger$
}

Department of Medical Microbiology, Royal London Hospital Trust, 37 Ashfield Street, London E1 1BB,

* Department of Oral Microbiology, St Bartholomew's and The Royal London School of Medicine and

Dentistry, Turner Street, London E1 2AD, †Gastrointestinal Science Research Unit, St Bartholomew's and The

Royal London School of Medicine and Dentistry, 26 Ashfield Street, London E1 2AJ and \$Department of

Epidemiology, St Bartholomew's and The Royal London School of Medicine and Dentistry, Turner Street,

London E1 1BB

To assess the influence of incubation conditions on the resistance of Helicobacter pylori this study compared the effect of micro-aerophilic and anaerobic incubation followed by micro-aerophilic incubation on the measurement of metronidazole resistance of 102 H. pylori isolates, by both disk diffusion and Epsilometer (E)-tests. Anaerobic incubation for $24 \mathrm{~h}$ before micro-aerophilic incubation for $48 \mathrm{~h}$ consistently increased metronidazole activity in both assay methods. Although statistically significant, this was microbiologically less significant, as only 4 of 102 isolates gave discrepant readings (all four were resistant in micro-aerophilic conditions but susceptible in anaerobic/micro-aerophilic conditions). In all four cases variation was by a few millimeters in zone size (i.e., all were close to the cut-off point). There was $100 \%$ agreement between disk diffusion and E-test results. Of 104 observations (52 duplicate assays: 13 strains, two atmospheric conditions, two methods of determining resistance) there was $100 \%$ intra-observer and inter-observer agreement with regard to susceptibility and resistance status for both $E$ test and disk diffusion methods. Anaerobic incubation followed by micro-aerophilic incubation had little effect on the estimation of prevalence of metronidazole resistance and seemed to add little, if any, significant advantage over micro-aerophilic incubation alone.

\section{Introduction}

An earlier study reported Helicobacter pylori metronidazole resistance levels of $90 \%$ in a UK Bangladeshi population when gastric biopsy isolates were assayed under micro-aerophilic conditions [1]. Recent reports suggest that strains resistant to metronidazole under micro-aerophilic atmospheric conditions become susceptible following prior anaerobic incubation [2-5]. This observation led us to question the validity of our initial conclusions [1] and the conclusions of others [6-8]. Therefore, the present study tested the null hypothesis that there was no difference in resistance

Received 5 May 1998; accepted 10 Aug. 1998.

Corresponding author: Dr N. Banatvala. Present address: Medical Emergency Relief International (MERLIN), 14 David Mews, Porter Street, London WIM 1HW (e-mail: nick.banatvala@merlin.org.uk). rates whether determined by micro-aerophilic incubation for $72 \mathrm{~h}$ or by anaerobic incubation for $24 \mathrm{~h}$ followed by micro-aerophilic incubation for $48 \mathrm{~h}$. This null hypothesis was tested with both the conventional disk diffusion assay and the Epsilometer (E)-test. The reproducibility of results was also determined.

\section{Materials and methods}

\section{H. pylori strains and culture}

Gastric H. pylori isolates used in this study $(\mathrm{n}=102)$ were collected from patients attending The Royal London Hospital endoscopy unit. The collection and primary culture of 100 of the 102 strains have been described previously [1]. Isolates were stored in liquid nitrogen as described previously [9]. H. pylori strain NCTC 11637 (National Collection of Type Cultures, 61 Colindale Avenue, London; type strain) was used as a control. As in the previous study [1] H. pylori NCTC 
strains 12822 and 12823 were used as metronidazolesusceptible and -resistant control strains, respectively. Bacteroides fragilis (NCTC 9343) and Pseudomonas aeruginosa (NCTC 10332) were used as obligate anaerobic and obligate aerobic control strains.

Frozen cultures were inoculated on to Brain Heart Infusion Agar (BHIA; CM375, Oxoid) containing defibrinated horse blood (Oxoid) $5-10 \%$ and $H$. pylori selective supplement (SR-147E Oxoid) containing $(/ \mathrm{L})$ vancomycin $10 \mathrm{mg}$, trimethoprim $5 \mathrm{mg}$, cefsulidin $5 \mathrm{mg}$ and amphotericin B $5 \mathrm{mg}$. Plates were incubated for 3 days in micro-aerophilic conditions $\left(\mathrm{O}_{2} 5 \%, \mathrm{CO}_{2} 5 \%\right.$ and $\left.\mathrm{N}_{2} 90 \%\right)$ created with a gas generating kit (Campylobacter system gas generating kit; Oxoid, BR42). The isolates were further subcultured on BHIA with defibrinated horse blood 5\% and incubated in micro-aerophilic conditions.

\section{H. pylori susceptibility testing and incubation conditions}

H. pylori colonies were harvested into Brucella Broth (0495-17-3; Difco, West Molesey) to obtain a turbidity equivalent to McFarland standard $4\left(c .10^{8} \mathrm{cfu} / \mathrm{ml}\right)$. A sterile cotton-tipped swab was dipped into the $H$. pylori suspension and streaked evenly across a Brucella Blood Agar (BBA; 0964-17-5; Difco) plate. The plates were briefly dried, then (i) a $5-\mu \mathrm{g}$ metronidazole disk (039820; Oxoid) was placed on the centre of two BA plates and (ii) a plastic metronidazole E-test strip (AB Biodisk, Solna, Sweden) was applied to another two BBA plates for each strain tested. One pair of plates (i.e., one disk diffusion and one E-test plate) was incubated in micro-aerophilic conditions for $72 \mathrm{~h}$ at $37^{\circ} \mathrm{C}$; the other pair was incubated in an anaerobic cabinet $\left(\mathrm{H}_{2} \quad 10 \%, \mathrm{CO}_{2} \quad 10 \%\right.$ and $\mathrm{N}_{2} 80 \%$; Don Whitely Scientific, Shipley) for $24 \mathrm{~h}$ at $37^{\circ} \mathrm{C}$, then in microaerophilic conditions for $48 \mathrm{~h}$. Control strains were included with all incubations.

\section{Interpretation of susceptibility tests}

For the disk diffusion test, isolates were considered resistant when the zone of clearance (edge of disk to edge of zone) was $\leqslant 10 \mathrm{~mm}$ around the metronidazole disk [1]. For the E-test, MICs were determined by the point of intersection of the zone of inhibition with the graded E-test strip according to the manufacturer's guidelines. Isolates were considered resistant when the MIC value was $\geqslant 8 \mathrm{mg} / \mathrm{L}$. E-test and disk diffusion readings were read independently of one another.

\section{Intra-observer and inter-observer variation}

Intra-observer variation was assessed with 13 strains (including three type strains), seven of which were metronidazole-resistant isolates and six were susceptible. Each strain was incubated under the two different atmospheric conditions with both E-test and disk diffusion as measures of resistance. Each assay was read on two separate occasions by one individual in a blinded fashion. Inter-observer variation was assessed with 10 strains different to those used in the intraobserver studies and also with the three type strains. As for the intra-observer assessment, seven were resistant isolates, six susceptible. Methods were as for assessing intra-observer variation.

\section{Statistical methods}

The Wilcoxon matched pairs signed ranked sum test for paired non-parametric data was used to compare zone diameters and MICs for the two atmospheric conditions $[10]$.

\section{Results}

The disk diffusion assay with incubation in microaerophilic conditions revealed metronidazole resistance in $60(59 \%)$ of 102 strains compared with 55 strains $(54 \%)$ in the original study [1]; $92 \%$ of isolates gave the same susceptibility pattern. Two strains were found to contain subpopulations of resistant and susceptible strains; one was recorded as susceptible and one as resistant in the original study.

Of the 102 strains incubated under both microaerophilic and anaerobic/micro-aerophilic conditions, four $(3.9 \%)$ produced discrepant results; all four were resistant in micro-aerophilic conditions but susceptible in anaerobic/micro-aerophilic conditions. In all four cases, variation was by a few millimeters in some size (i.e., all were close to the cut-off point). There was $100 \%$ agreement between disk diffusion and E-test results (including the discrepancy of the four isolates above) when the different atmospheric incubation conditions were compared.

Anaerobic incubation for $24 \mathrm{~h}$ before micro-aerophilic incubation for $48 \mathrm{~h}$ gave consistently larger zones of clearance in the disk diffusion assay and lower MIC values in the E-test (Table 1). Although statistically significant, this was microbiologically less significant, as can be seen both in the variation in readings under the two different incubation conditions, and the overall change in resistance status of the 102 isolates.

\section{Intra-observer and inter-observer variation}

Of 104 observations (52 duplicate assays: 13 strains, two atmospheric conditions, two methods for determining resistance) there was $100 \%$ intra-observer agreement for susceptibility and resistance status. All except one of the 26 duplicate E-test readings were identical; the exception gave E-test MIC values of 1.5 and $2 \mathrm{mg} / \mathrm{L}$. Twenty of 26 duplicate disk diffusion diameter readings were identical to within $1 \mathrm{~mm}$. Of the six discrepant pairs, variation was as follows: $35 \mathrm{~mm}$ 
Table 1. Relationship between metronidazole disk diffusion and E-test assays for $102 \mathrm{H}$. pylori strains incubated micro-aerophilically for $72 \mathrm{~h}$ and anaerobically for $24 \mathrm{~h}$ followed by micro-aerophilic incubation for $48 \mathrm{~h}$

\begin{tabular}{llrr}
\hline & Incubation & \multicolumn{2}{c}{$\begin{array}{c}\text { Zone size or MIC } \\
\text { of resistant } \\
\text { strains }\end{array}$} \\
\cline { 3 - 4 } Assay & conditions & Median & Inter-quartile range \\
\hline Disk diffusion & Micro-aerophilic & $2 \mathrm{~mm}$ & $0-18 \mathrm{~mm}$ \\
Disk diffusion & Anaerobic/micro-aerophilic & $7 \mathrm{~mm}$ & $0-23.5 \mathrm{~mm}$ \\
E-test & Micro-aerophilic & $32 \mathrm{mg} / \mathrm{L}$ & $2-32 \mathrm{mg} / \mathrm{L}$ \\
E-test & Anaerobic/micro-aerophilic & $28 \mathrm{mg} / \mathrm{L}$ & $56(55)$ \\
\hline
\end{tabular}

$\mathrm{p}=0.0001$, Wilcoxon matched pairs signed ranked sum test to compare zone of clearance with disk diffusion assay under micro-aerophilic incubation versus anaerobic/micro-aerophilic incubation (agreement $96 \%$ ); $p=0.001$, Wilcoxon matched pairs signed ranked sum test to compare MIC of E-test assay under micro-aerophilic incubation versus anaerobic/micro-aerophilic incubation (agreement $96 \%$ ); concordance of susceptibility result between E-test and disk diffusion assays $=100 \%$.

versus $36 \mathrm{~mm}, 30 \mathrm{~mm}$ versus $32 \mathrm{~mm}, 12 \mathrm{~mm}$ versus $15 \mathrm{~mm}, 28 \mathrm{~mm}$ versus $30 \mathrm{~mm}, 22 \mathrm{~mm}$ versus $26 \mathrm{~mm}$ and $37 \mathrm{~mm}$ versus $38 \mathrm{~mm}$. Where such variation occurred it appeared to be systematic, with the first of the two readings being recorded as the lower value.

There was $100 \%$ inter-observer agreement for susceptibility and resistance status with both E-test and disk diffusion methods; 23 (88\%) of 26 duplicate E-test readings were identical. Discrepant readings were as follows: 0.38 versus $0.25 \mathrm{mg} / \mathrm{L} ; 0.75$ versus $0.65 \mathrm{mg} / \mathrm{L}$ and 0.19 versus $0.125 \mathrm{mg} / \mathrm{L}$. Nineteen $(73 \%)$ of 26 duplicate disk diffusion diameter readings were identical to within $1 \mathrm{~mm}$. Of the discrepant pairs, variation was random, four were discrepant by $1 \mathrm{~mm}$ and two by $2 \mathrm{~mm}$.

\section{Discussion}

Concern has been expressed at the lack of standardised methods for assessing metronidazole resistance in $H$. pylori [4]. This is important, as it may partially explain the wide variation in reported resistance rates both between and within different countries. However, several studies based on disk diffusion under microaerophilic conditions have shown an association between metronidazole resistance and lower $H$. pylori eradication rates following therapies which included metronidazole [11-14] and this would suggest that these methods have clinical importance.

Data from the present study suggest that the results from the original study [1] remain valid and that a 24 $h$ period of anaerobic incubation before microaerophilic incubation in a population-based survey does not appreciably alter the proportion of isolates recorded as metronidazole susceptible. However, anaerobic pre-incubation did enhance the activity of metronidazole, and although this was statistically significant, it was only occasionally ( $4 \%$ in this study) of apparent microbiological significance, i.e., for isolates with a zone of inhibition or MIC that is close to the cut-off point for resistance. The viability of $H$. pylori after anaerobic incubation for $24 \mathrm{~h}$ was not assessed.
The data in Table 1 suggest that many $H$. pylori were killed by the increased uptake of the drug in anaerobic conditions. These data fit with observations suggesting that the nitro group in metronidazole is reduced in anaerobic conditions, resulting in a product that damages the DNA of $H$. pylori and results in cell death [15]. It is uncertain whether this process occurs in micro-aerophilic conditions or whether the reduced metronidazole is converted back to its parent compound by futile cycling [3]. In contrast, other studies have shown a much greater effect following a 24-h anaerobic pre-incubation period $[2,3,16,17]$. This difference may be a reflection of the larger number of strains tested in the present study. The effect of a higher $H$. pylori inoculum density on metronidazole resistance was not investigated in the present study.

While some reports suggest that E-test results correlate with disk diffusion and agar dilution assays for $H$. pylori [2, 17-19], others have not shown such a good association $[18,20]$. The data in the present study suggest that the association between the two methods is good. The reproducibility of both methods is demonstrated by the good agreement in intra- and inter-observer comparisons.

In conclusion, while anaerobic conditions marginally increased the susceptibility of $H$. pylori to metronidazole in comparison with micro-aerophilic incubation, its effects on the measured prevalence of metronidazole resistance in over 100 gastric isolates were minimal. These findings validate the conclusions of earlier studies $[1,6-8]$ examining the prevalence of metronidazole resistance of $H$. pylori in microaerophilic incubation conditions.

\section{References}

1. Banatvala N, Davies GR, Abdi Y et al. High prevalence of Helicobacter pylori metronidazole resistance in migrants to east London: relation with previous nitroimidazole exposure and gastroduodenal disease. Gut 1994; 35: 1562-1566.

2. Cederbrant G, Kahlmeter G, Ljungh A. Proposed mechanism for metronidazole resistance in Helicobacter pylori. $J$ Antimicrob Chemother 1992; 29: 115-120.

3. Edwards DI, Smith MA. The influence of microaerophilia and anaerobiosis on metronidazole uptake in Helicobacter pylori. 
J Antimicrob Chemother 1995; 36: 453-461.

4. Smith MA, Edwards DI. Redox potential and oxygen concentration as factors in the susceptibility of Helicobacter pylori to nitroheterocyclic drugs. $J$ Anitimicrob Chemother 1995; 35: 751-764.

5. van Zwet AA, Thijs JC, de Graaf B. Explanations for high rates of eradication with triple therapy using metronidazole in patients harboring metronidazole-resistant Helicobacter pylori strains. Antimicrob Agents Chemother 1995; 39: 250-252.

6. Becx MCJM, Janssen AJHM, Clasener HAL, De Koning RW. Metronidazole-resistant Helicobacter pylori. Lancet 1990; 335: 539-540.

7. Glupczynski Y, Burette A, De Koster E et al. Metronidazole resistance in Helicobacter pylori. Lancet 1990; 335: 976-977.

8. Goodwin CS, Marshall BJ, Blincow ED, Wilson DH, Blackbourn S, Phillips M. Prevention of nitroimidazole resistance in Campylobacter pylori by coadministration of colloidal bismuth subcitrate: clinical and in vitro studies. J Clin Pathol 1988; 41: $207-210$.

9. Drumm B, Sherman P. Long-term storage of Campylobacter pylori. J Clin Microbiol 1989; 27: 1655-1656.

10. Altman DG. Practical statistics for medical research, 1st edn. London, Chapman and Hall. 1991.

11. Logan RP, Gummett PA, Misiewicz JJ, Karim QN, Walker $\mathrm{MM}$, Baron $\mathrm{JH}$. One week eradication regimen for Helicobacter pylori. Lancet 1991; 338: 1249-1252.

12. Noach LA, Langenberg WL, Bertola MA, Dankert J, Tytgat GNJ. Impact of metronidazole resistance on the eradication of Helicobacter pylori. Scand J Infect Dis 1994; 26: 321-327.
13. Rautelin H, Seppälä K, Renkonen O-V, Vainio U, Kosunen TU. Role of metronidazole resistance in therapy of Helicobacter pylori infections. Antimicrob Agents Chemother 1992; 36: $163-166$.

14. Weil J, Bell GD, Powell $\mathrm{K}$ et al. Helicobacter pylori infection treated with a tripotassium dicitrato bismuthate and metronidazole combination. Aliment Pharmacol Ther 1990; 4: 651-657.

15. Edwards DI. Nitroimidazole drugs - action and resistance mechanisms. I Mechanisms of action. J Antimicrob Chemother 1993; 31: 9-20.

16. Asaka M, Kimura $\mathrm{T}$, Kato $\mathrm{M}$ et al. Possible role of Helicobacter pylori infection in early gastric cancer development. Cancer 1994; 73: 2691-2694.

17. Glupczynski Y, Labbe M, Hansen W, Crokaert F, Yourassowsky E. Evaluation of the $\mathrm{E}$ test for quantitative antimicrobial susceptibility testing of Helicobacter pylori. J Clin Microbiol 1991; 29: 2072-2075.

18. Hirschl AM, Hirschl MM, Rotter ML. Comparison of three methods for the determination of the sensitivity of Helicobacter pylori to metronidazole. I Antimicrob Chemother 1993; 32: 45-49.

19. Xia HX, Daw MA, Beattie S, Keane CT, O'Morain CA. Prevalence of metronidazole-resistant Helicobacter pylori in dyspeptic patients. Ir J Med Sci 1993; 162: 91-94.

20. Von Recklinghausen G, Ansorg R. Metronidazole susceptibility testing of Helicobacter pylori with the PDM epsilometer test (E test). Int J Med Microbiol Virol Parasitol Infect Dis 1995; 282: $83-85$. 